\title{
A coleta de resíduos orgânicos domésticos para o controle de doenças sinantrópicas transmitidas por vetores no município de Ipixuna do Pará, nordeste paraense
}

\author{
The collection of household organic waste for the control of synanthropic vector-borne diseases in \\ the municipality of Ipixuna do Pará, northeast Pará \\ La recolección de residuos orgánicos domésticos para el control de enfermedades sinantrópicas \\ transmitidas por vectores en el municipio de Ipixuna do Pará, noreste de Pará
}

Recebido: 28/04/2021 | Revisado: 05/05/2021 | Aceito: 16/05/2021 | Publicado: 03/06/2021

\author{
Andreia Fernandes Gonçalves \\ ORCID: https://orcid.org/0000-0002-0580-6367 \\ Universidade do Estado do Pará, Brasil \\ E-mail: andreiabiologia17@gmail.com \\ Jaqueline Prestes de Cristo \\ ORCID: https://orcid.org/0000-0002-0670-8240 \\ Universidade do Estado do Pará, Brasil \\ E-mail: jaquelineprestes6@gmail.com \\ Antônio Pereira Júnior \\ ORCID: https://orcid.org/0000-0001-6241-985X \\ Universidade do Estado do Pará, Brasil \\ E-mail: antonio.junior@uepa.br
}

\begin{abstract}
Resumo
A coleta de resíduos orgânicos é importante para garantir o bem-estar da comunidade, quando esse serviço não ocorre ou são feitos de forma inadequada, desencadeiam uma série de problemas à população e ao meio ambiente. O objetivo dessa pesquisa a realização de uma análise qualitativa e quantitativa acerca da influência do lixo na proliferação de vetores causadores de patologias que agravam a saúde pública. Para isso, empregou-se o método comparativo, com abordagem quantitativa e qualitativa. Os dados primários foram obtidos in sito. Para obtenção dos dados secundários fez-se um levantamento dos dados documentais em links de acesso livre como o portal de periódicos da Coordenação de Pesquisa do Ensino Superior (CAPES) e Scientific Eletronic Library Online (SciELO), e limitou-se o recorte temporal entre 2008 e 2020. Os dados obtidos e analisados indicaram que: (1) a coleta do lixo é eficiente quando se trata de um bairro próximo a grandes pontos comerciais, porém nos bairros periféricos esses serviços são precários; (2) ocorre o acúmulo de lixo em locais inadequados e influencia consideravelmente no aparecimento de vetores. Concluise que existe a falta de sensibilização da população, com relação ao lixo, já que muitos moradores mesmo tendo a coleta de segunda a sexta, promovem disposição final do lixo em locais inapropriados; outro fato é a embalagem inadequada, ou seja, em sacolas plásticas, quando disposto à coleta municipal, o que facilmente pode ser rasgadas por animais e, com isso, atraem vetores com mais facilidade, o que incrementa a disseminação de doenças na comunidade. Palavras-chave: Vetores; Resíduos orgânicos; Saúde pública.
\end{abstract}

\begin{abstract}
The collection of organic waste is important to ensure the welfare of the community, when this service does not occur or is done improperly, it triggers a series of problems to the population and the environment. The objective of this research was to perform a qualitative and quantitative analysis of the influence of garbage in the proliferation of vectors that cause pathologies that aggravate public health. For this, the comparative method was used, with a quantitative and qualitative approach. The primary data was obtained in situ. To obtain secondary data, a survey of documental data was carried out using open access links, such as the periodical portal of the Coordination for Higher Education Research (CAPES) and the Scientific Electronic Library Online (SciELO), and the time frame was limited to 2008 and 2020. The data obtained and analyzed indicated that: (1) garbage collection is efficient when it comes to a neighborhood near major commercial points, but in peripheral neighborhoods these services are precarious; (2) there is the accumulation of garbage in inappropriate places and considerably influences the appearance of vectors. It is concluded that there is a lack of awareness of the population, with respect to garbage, since many residents even having collection from Monday to Friday, promote final disposal of garbage in inappropriate places; another fact is the inadequate packaging, i.e., in plastic bags, when disposed of the municipal collection, which can easily be torn by animals and thus attract vectors more easily, which increases the spread of diseases in the community.
\end{abstract}

Keywords: Vectors; Public health; Organic waste. 


\begin{abstract}
Resumen
La recogida de residuos orgánicos es importante para garantizar el bienestar de la comunidad, cuando este servicio no se realiza o se hace de forma inadecuada, se desencadenan una serie de problemas para la población y el medio ambiente. El objetivo de esta investigación fue realizar un análisis cualitativo y cuantitativo de la influencia de la basura en la proliferación de vectores causantes de patologías que agravan la salud pública. Para ello, se empleó el método comparativo, con un enfoque cuantitativo y cualitativo. Los datos primarios se obtuvieron en sito. Para la obtención de datos secundarios, se realizó un relevamiento de datos documentales en enlaces de libre acceso como el portal de revistas de la Coordinación de Investigación en Educación Superior (CAPES) y Scientific Electronic Library Online (SciELO), y el marco temporal se limitó entre 2008 y 2020. Los datos obtenidos y analizados indicaron que: (1) la recogida de basura es eficiente cuando se trata de un barrio cercano a los principales puntos comerciales, pero en los barrios periféricos estos servicios son precarios; (2) se produce la acumulación de basura en lugares inadecuados e influye considerablemente en la aparición de vectores. Se concluye que existe una falta de concienciación de la población, con respecto a la basura, ya que muchos residentes incluso teniendo la recogida de lunes a viernes, promueven la disposición final de la basura en lugares inadecuados; otro hecho es el embalaje inadecuado, es decir, en bolsas de plástico, cuando se dispone de la recogida municipal, que puede ser fácilmente arrancado por los animales y, por lo tanto, atraer a los vectores más fácilmente, lo que aumenta la propagación de enfermedades en la comunidad.
\end{abstract}

Palabras clave: Vectores; Residuos orgánicos; Salud pública.

\title{
1. Introdução
}

O início da industrialização na Inglaterra ocorreu no século XVIII, o que gerou um crescimento descontrolado, e proporcionou um grande e repentino crescimento populacional nas áreas urbanas, devido à migração interna (zona rural- para zona urbana), consequentemente originou a produção exacerbada dos resíduos sólidos, especialmente o doméstico. Atrelado a esse fato, o lixo se tornou uma grande problemática social e ambiental, pois, sem o investimento necessário para um descarte adequado, o lixo doméstico passou a ser depositado em locais inadequados (Pereira Júnior et al., 2018).

Acerca dessa ação, os estudos (Bessa et al., 2020; Silva et al., 2017; Silva et al., 2020) indicam que ela culmina em diversos problemas como, por exemplo, proliferação de vetores, estes são capazes de transmitir agentes infectantes. Outro fator, está relacionado a quantidade diária gerada ou pelas dificuldades inerentes a coleta seletiva/não, a destinação e a disposição final, sem que haja um tratamento adequado para tais resíduos (Schleder \& Albuquerque, 2016).

Quanto a proliferação de vetores, sabe-se que ela ocorre porque a disposição final dos RS's em vazadouros a céu aberto (lixões) torna-se uma área para alimentação e reprodução deles, além de bactérias e fungos de importância epidemiológica e transmissores de doenças como leishmaniose, febre amarela, malária, cólera, doenças respiratórias, dentre outras (Naime, 2014).

Outro fator negativo da ineficiência na coleta seletiva, está relacionada a proliferação de animais sinantrópicos que, para isso, precisam, principalmente, ter acesso à água, a abrigo e alimento. Dentre os inúmeros animais vertebrados assim classificados, tem-se o rato (Ratus spp) que biologicamente, possui um metabolismo eclético, já, que digere classes diferentes de alimentos, seja de origem vegetal quanto animal. Ele é capaz de transmitir, através da urina e fezes, enfermidades como leptospirose e peste bubônica (Ribeiro \& Rooke, 2010).

No caso de invertebrados sinantrópicos, tem-se a barata que, das 644 espécies presentes no Brasil, menos de 20 são classificadas daquela forma, dentre elas, encontram-se as espécies Blatella germânica (Linnaeus, 1758) e a Periplaneta americana (Linnaeus, 1758), de hábitos noturnos, são habituadas a ambientes domésticos e transmitem doenças como o tifo, disenteria, hepatite, alergias, lepra, além de 60 tipos de parasitas (Firmo, 2010).

Nesse contexto, a coleta dos RS's, que é um dos componentes do saneamento básico e, de acordo com a Lei n. ${ }^{\circ}$ 14.026 (BRASIL, 2020), torna-se uma das ferramentas mais eficazes para mitigar a proliferação dos vetores e a elevação das taxas daquelas doenças. Porém, dos 5.570 municípios brasileiros, a coleta seletiva ainda é incipiente, assim como no município de Ipixuna (Maciel et al., 2015) 
Outro aspecto, acerca dos animais sinantrópicos é a ineficiência na coleta de resíduos sólidos, envolve a ecologia dessa comunidade porque os RS's tornam-se um habitat à instalação, reprodução e sobrevida porque ocupam nichos ecológicos distintos, pois, a capacidade de adaptação deles, é real (Santos, 2010). Tudo isso, comprova que a diversidade desses animais (ratos, pombos, moscas, pulgas, escorpiões, aranhas, formigas, centopeias, taturanas, mosquitos, abelhas, vespas e morcegos), bem como o impacto negativo sobre a saúde humana, provocado por ações antrópicas negativas provocadas por ele mesmo (PMSP, 2014).

Consequentemente, a coleta de resíduos orgânicos é importante para garantir o bem-estar da comunidade, tanto urbana quanto rural. Assim, quando esse serviço não ocorre ou são feitos de forma inadequada, desencadeiam uma série de problemas à população e ao meio ambiente, pois, no período chuvoso, há produção de chorume, cujo principal impacto é a contaminação das águas subterrâneas e a contribuição para o incremento das doenças causadas por ingestão de águas contaminadas (Follador et al., 2015).

Logo, o aumento da produção e a má disposição de resíduos domésticos, principalmente na zona urbana causam uma série de problemas ambientais que afetam diretamente o meio ambiente e a saúde pública, o que justificou e incrementou a relevância desse estudo, cujo objetivo, foi a análise qualitativa e quantitativa da influência do lixo na proliferação de vetores causadores de patologias que agravam a saúde pública e assim, gerar dados para outras pesquisas ou monitoramento desta problemática.

\section{Material e Métodos}

\subsection{Local da pesquisa}

O estudo foi realizado no município de Ipixuna do Pará (Figura 1), localizado no nordeste paraense às margens da BR-010 e distante cerca de $250 \mathrm{~km}$ de capital Belém. Ipixuna do Pará tem uma população estimada em 56.613 habitantes, distribuídos em 5.215,555 km² de área e com 12.227 mil pessoas residentes na zona urbana (Gutjahr, 2014). O município faz parte da mesorregião Nordeste do estado do Pará, na qual faz parte dos treze municípios pertencentes a microrregião do Guamá.

Figura 1. Localização do município de Ipixuna do Pará e os municípios limítrofes, nordeste paraense.

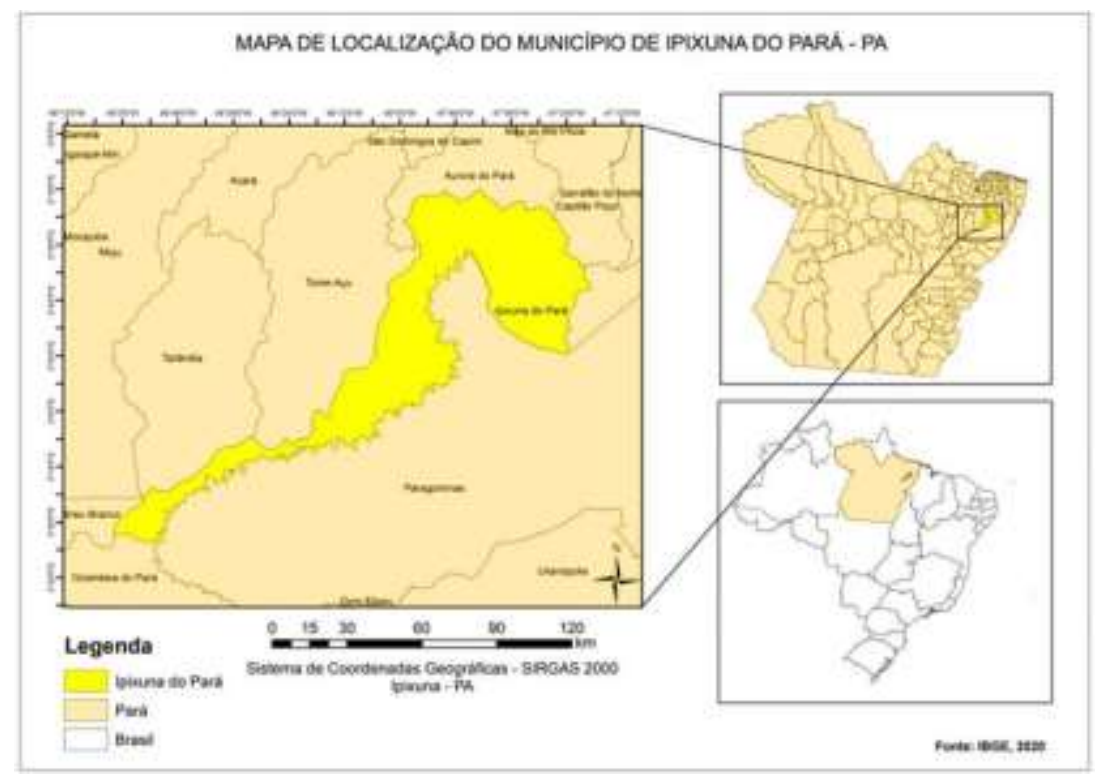

Fonte: Autores (2021). 
Ipixuna do Pará, como pode ser observado na Figura 1, apresenta limites geográficos com o município de Paragominas, onde o desenvolvimento da sojicultora apresenta amplo desenvolvimento já em 2017, 31,56\% (IBGE, 2018). Esse crescimento tem provocado deslocamento de trabalhadores rurais que podem estar residindo em ambos os municípios. Outro local de origem deles, pode ser Aurora do Pará, que faz limites ao norte do município objeto dessa pesquisa.

\subsection{Método}

O método utilizado neste estudo foi comparativo, de acordo a síntese escrita por Prodanov e Freitas (2013). Eles afirmam que a aplicação dele, tem como objetivo analisar as diferenças e as similaridades, e realizar uma investigação detalhada, dos fenômenos, indivíduos ou fatos e, finalmente, promover uma comparação entre eles. Dessa forma, a utilização dele possibilita a verificação das semelhanças e divergências de grandes grupamentos sociais, que são separados pelo espaço e pelo tempo.

Em relação a abordagem, o estudo é de caráter quantitativo e qualitativo porque Oliveira (2011) afirma que, o primeiro é caracterizado pelo emprego numérico tanto de coleta de informações sejam elas primárias ou secundárias, bem como pode ser empregado no tratamento estatísticos dos dados obtidos. Já o segundo, busca o significado para interpretação dos dados quantitativos. Desse modo uso das duas abordagens foi em razão de relacionar os valores numéricos para melhor analisar a percepção da população em relação a temática lixo. Quanto a amostragem, adotou-se o descrito por Pereira et al. (2018). Esses autores afirmam que a estatística como tratamento quantitativo dos dados, só poderá ser aplicada quando há um espaço temporal pré-determinado e um conjunto de dados advindos desse local. Nessa pesquisa, praticou-se tanto a primeira quanto a segunda condição.

\subsection{Coleta de dados}

A pesquisa de campo foi realizada nos dias 03, 04, 05 e 06 de fevereiro de 2021, com objetivo de entrevistar a população para obtenção de dados relacionado a produção, coleta e destinação dos resíduos produzidos. A obtenção dos dados ocorreu com a comunidade de dois bairros do município, a escolha dos dois bairros se deu de forma aleatória, sendo que um bairro fica localizado no centro (Centro) e outro na região periférica do município, denominado João Paulo II (Figura 2). 
Figura 2. Localização das áreas onde a pesquisa foi realizada. Ipixuna do Pará, nordeste paraense.

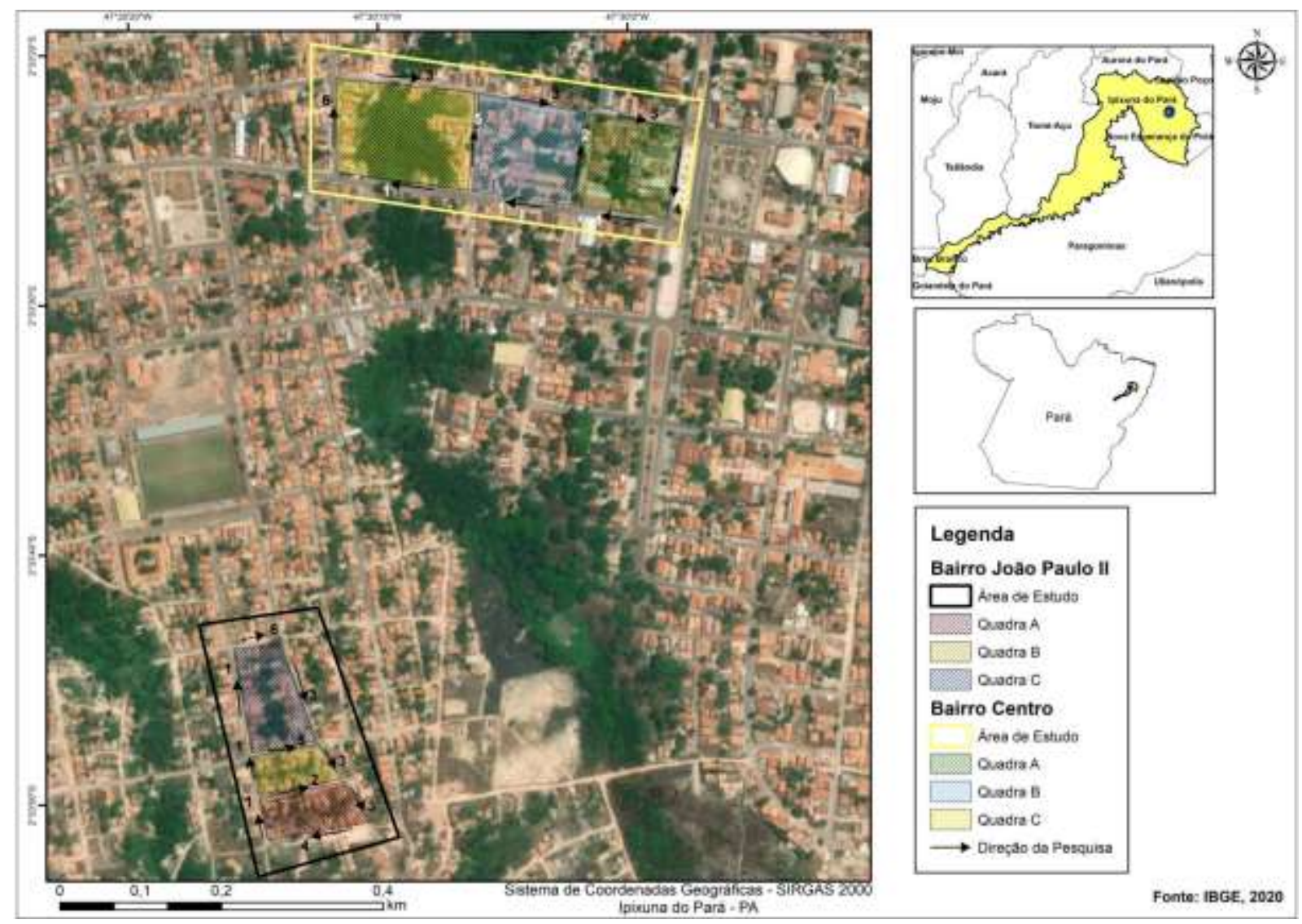

Legendas: Bairro Centro; 1: Travessa Padre José de Anchieta; 2: Rua Antônio Gomes de Araújo; 3: Travessa Jarbas Passarinho; 4: Avenida Presidente Getúlio Vargas; 5: Rua Manoel do Carmo; 6: Rua João Honorato da Costa. Bairro João Paulo II; 1: Rua D; 2: Rua Alameda; 3: Rua E; 4: Travessa da Paz; 5: Rua Q, e 6: Travessa O. Fonte: Autores (2021).

Na Figura 2, percebe-se que o bairro Centro (retângulo amarelo) é marginal à Rodovia BR 010, por isso apresenta um concentração mais efetiva quanto a hotéis, pensões para pernoites, restaurantes, lanchonetes, e vendas a varejo e atacado, além das paradas de ônibus intermunicipais e estaduais que ocorrem às margens dessa rodovia, o que favorece a produção de um volume de resíduos sólidos mais elevado, o que já não ocorre com o bairro João Paulo II (retângulo preto), já periférico quando comparado ao Centro, e com menor número de comércios atacadistas, e comunidade com baixa renda per capita, logo, a quantidade de RS's geradas pode ser mais baixa.

A coleta de dados primários foi realizada a partir de 146 entrevistas de caráter formal com a comunidade, os moradores foram abordados em suas próprias residências e procurou-se entrevistar principalmente os donos dos domicílios selecionados para o estudo, o formulário foi composto por nove subitens, constituído por perguntas acerca da percepção da população a respeito do problema "lixo" no município (Figura 3). 
Figura 3. Número e conteúdo das questões efetivadas durante a entrevista informal. Ipixuna do Pará, nordeste paraense.

\begin{tabular}{|c|c|c|c|}
\hline \multicolumn{4}{|c|}{$\begin{array}{l}\text { UNIVERSIDADE DOESTADO DO PARÁ } \\
\text { CENTRO DE CIÊNCLAS SOCIAIS E EDUCAÇÂAO } \\
\text { DEPARTAMENTO DE BIOLOGLA } \\
\text { CAMPUS VIPARAGOMINAS }\end{array}$} \\
\hline \multicolumn{4}{|c|}{ Trabalho de Conclusão do curso } \\
\hline \multicolumn{4}{|c|}{ Pesquisa de dados primários } \\
\hline Questão & Earedo & \multicolumn{2}{|c|}{ Respostas } \\
\hline 1 & Você separa o lixo produrido na sua casa? & () $\sin$ & () กล̃o \\
\hline \multirow{5}{*}{2} & $\begin{array}{l}\text { Você considera a questäo lixo um problema no } \\
\text { bairro onde vive? }\end{array}$ & () $\operatorname{sim}$ & () กล̃ \\
\hline & Nesse bairro, o lixo é coletado? & () $\sin { }^{2} 5$ & () não \\
\hline & Você considera essa quantidade suficiente? & () $\sin$ & () กล̃o \\
\hline & $\begin{array}{l}\text { Vooê conhece ou já ouviu falar de coleta } \\
\text { seletiva? }\end{array}$ & () $\sin$ & ( ) กล̃o \\
\hline & Essa coleta é do tipo seletiva & () $\operatorname{sim}$ & () กล̃o \\
\hline 3 & Quantas vezes o lixo é coletado? & () semanalmente & $\begin{array}{l}\text { () não é } \\
\text { ccletado }\end{array}$ \\
\hline 4 & $\begin{array}{l}\text { Vocé sabe onde colocam o lixo depois de } \\
\text { coletado }\end{array}$ & () $\sin$ & ( ) กล̃o \\
\hline 5 & $\begin{array}{l}\text { Essa não coleta, vocé acredita que proroca o } \\
\text { aparecimento, na sua casa, de: }\end{array}$ & $\begin{array}{l}\text { () Ratos } \\
\text { () Baratas } \\
\text { () Mosquitos } \\
\text { () Moscas }\end{array}$ & \\
\hline 6 & $\begin{array}{l}\text { Voce sabe que esses animais podem transmitir } \\
\text { doencas aos moradores? Se corhece, por favor, } \\
\text { indique uma. }\end{array}$ & & \\
\hline 7 & $\begin{array}{l}\text { Quanto ao lixo produzido na sua casa, quais os } \\
\text { mais frequente? }\end{array}$ & $\begin{array}{l}\text { () restos de } \\
\text { alimentos } \\
\text { () plasticos } \\
\text { () papel } \\
\text { () latas } \\
\text { () vidros }\end{array}$ & \\
\hline 8 & $\begin{array}{l}\text { Como vocé embala o lixo produzido na sua } \\
\text { casa? }\end{array}$ & $\mathrm{R}$ : & \\
\hline 9 & $\begin{array}{l}\text { Desses lixos que rocê produz na sua casa que } \\
\text { podem ser reaproveitados, reutilizados ou } \\
\text { vendidos para evitar a proliferaçâo de animais } \\
\text { causadores de doenças? }\end{array}$ & R: & \\
\hline
\end{tabular}

Fonte: Autores (2021).

As questões contidas no formulário aplicado nessa pesquisa, expostas na Figura 3, foram elaboradas para obtenção de informações da própria comunidade quanto ao lixo que eles produzem, como os embalam, a questão da coleta, e a destinação/disposição final. De acordo com Jacinski (2017), a construção do conhecimento não deve ocorrer de forma desordenada, por isso, cada uma das questões foram alocadas na ordem apresentadas naquela figura.

Esse método foi associado a um levantamento de dados documentais em periódicos nacionais, com recorte temporal entre 2008 e 2020, ou seja, de 12 anos. Para melhor análise dos temas: coleta de resíduos orgânicos, proliferação de vetores (vertebrados e invertebrados) e disseminação de doenças. Os links em que foi efetuada a seleção das literaturas, foram aqueles de acesso livre como: Scientific Eletronic Library Online (SciELO) e o Portal de Periódicos da Coordenação de Pesquisa do Ensino Superior (CAPES).

Para melhor compreensão sobre a aplicação da metodologia, foi elaborado um fluxograma que aborda as etapas do estudo (Figura 4). 
Figura 4. Fluxograma das etapas de aplicação da metodologia utilizada nesta pesquisa. Ipixuna do Pará, nordeste paraense.

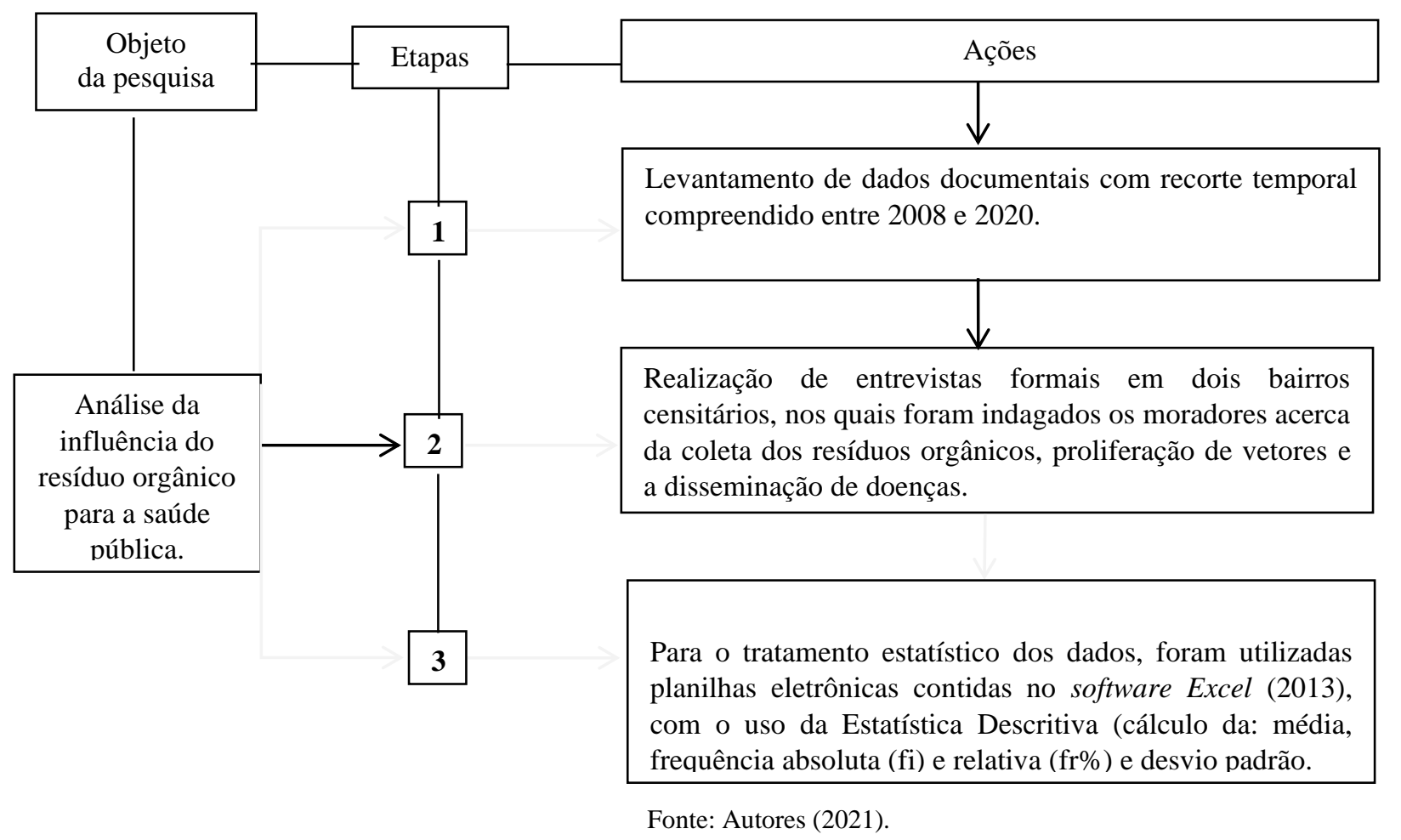

As etapas de execução dessa pesquisa ordenadas na Figura 4, permitiram uma fluidez na ordenação e desenvolvimento e definição do modus operandis desse trabalho, desde a busca de informações secundárias até o cálculo final de todos os dados obtidos após as 146 entrevistas formais realizadas e, com isso houve maior facilidade quanto a apresentação dos resultados e discussão acerca do problema do lixo em Ipixuna do Pará.

\section{Resultados e Discussão}

\subsection{Obtenção dos dados primários - tipos de unidades arquitetônicas}

Os dados obtidos e analisados quanto ao tipo de unidades arquitetônicas objetos dessa pesquisa, indicaram três tipos, para os dois bairros analisados, nas três quadras envolvidas (Tabela 1).

Tabela 1. Tipos e quantitativos de unidades arquitetônicas identificadas. Ipixuna do Pará, nordeste paraense.

\begin{tabular}{ccccccc}
\cline { 2 - 7 } & \multicolumn{5}{c}{ Centro } & \multicolumn{3}{c}{ João Paulo II } \\
\cline { 2 - 7 } & QA & QB & QC & QA & QB & QC \\
\hline & $\bar{x}_{ \pm \sigma}$ & $\bar{x}_{ \pm \sigma}$ & $\bar{x}_{ \pm \sigma}$ & $\bar{x}_{ \pm \sigma}$ & $\bar{x}_{ \pm \sigma}$ & $\bar{x}_{ \pm \sigma}$ \\
\hline ER & $4,3 \pm 1,3$ & $5,8 \pm 2,5$ & $4,3 \pm 2,2$ & $5,8 \pm 1,5$ & $5,5 \pm 1,3$ & $5,3 \pm 1,5$ \\
EC & $1,0 \pm 0,0$ & $0,0 \pm 0,0$ & $1,5 \pm 0,6$ & $1,0 \pm 0,5$ & $1,0 \pm 0,5$ & $1,5 \pm 0,9$ \\
& & & & & & \\
MI & $0,8 \pm 0,5$ & $0,5 \pm 0,5$ & $0,8 \pm 1,0$ & $0,0 \pm 0,0$ & $0,0 \pm 0,0$ & $0,0 \pm 0,0$ \\
\hline
\end{tabular}

Legendas: ER (Estritamente Residencial); EC (Estritamente Comercial); MI (Mista). Fonte: Autores (2021).

Na pesquisa realizada em Ipixuna do Pará, o número total de unidades arquitetônicas equivale a 153. Em relação aos dois bairros, o denominado "Centro" é composto por 79 unidades arquitetônicas, e a maioria $(n=75,0 ; 94,9 \%)$ foi 
entrevistada: ER, $n=57,0 ; 76,0 \%$; EC, $n=10,0 ; 13,3 \%$; MI, $n=8,0 ; 10,6 \%$. Uma pequena parcela $(n=4,0 ; 5,0 \%)$, optaram por não participar $(n=2,0 ; 2,5)$, ou as ER's estavam fechadas $(n=2,0 ; 2,5 \%)$.

No outro bairro, o João Paulo II, as quadras presentes na área de estudo são compostas de 74 unidades arquitetônicas, destas $(\mathrm{n}=71,0 ; 95,9 \%)$ foi entrevistada: (ER, $n=66,0 ; 92,9 \%$; EC, $n=5,0 ; 7,1 \%$; MI, $n=0,0 ; 0,0 \%)$. Com relação as unidades arquitetônicas restantes $(n=3,0 ; 4,1 \%)$, não participaram por opção $(n=2,0 ; 2,7 \%)$, ou as ER`s estava fechada ( $\mathrm{n}=$ $1,0 ; 1,4 \%)$.

Acerca dessa abordagem, Britto Júnior e Feres Júnior (2011) sintetizaram que nesse tipo de procedimento, deve-se objetivar a busca pelo conhecimento disponível sobre o problema formulado, de modo que haja respostas para ele. Nessa pesquisa, o problema em Ipixuna do Pará, foi a coleta de lixo no município, e os residentes dele sabem qual o estágio do problema e as consequências nos cotidianos deles, logo, a técnica utilizada esteve em consonância com o argumento escrito por aqueles dois autores.

\subsection{Análise das questões}

\subsubsection{Questão 1 (Você separa o lixo?)}

A análise dos dados obtidos indicou que, nos dois bairros objetos dessa pesquisa, os indivíduos amostrados (bairro Centro, 25,0 $\pm 0,8$; bairro João Paulo II, 26,7 $\pm 0,5)$, afirmaram que não separam o lixo produzido nas residências deles $(n=$ $146,0 ; 100,0 \%)$. Isso deve-se ao fato de que, em Ipixuna do Pará, não tem coleta seletiva (Tabela 2).

Tabela 2. Valores obtidos sobre a separação de lixo. Ipixuna do Pará, nordeste paraense.

\begin{tabular}{|c|c|c|c|c|}
\hline \multirow[b]{2}{*}{ Subitens } & \multicolumn{2}{|c|}{ Sim } & \multicolumn{2}{|c|}{ Não } \\
\hline & \multicolumn{2}{|c|}{$\cdots-\bar{x} \pm \sigma \ldots$} & \multicolumn{2}{|c|}{$\cdots \bar{x} \pm \sigma \ldots$} \\
\hline & Centro & João Paulo II & Centro & João Paulo II \\
\hline Você separa o lixo? & $0,0 \pm 0,0$ & $0,0 \pm 0,0$ & $25,0 \pm 0,8$ & $26,7 \pm 0,5$ \\
\hline
\end{tabular}

Fonte: Autores (2021).

A partir da análise dos dados em relação a separação dos resíduos sólidos, tanto no centro como no bairro João Paulo II, a diferença estatística entre os mesmos não foi significativa (1,8\%). Isso mostra que em ambas as localidades, a percepção ambiental quanto a importância da separação de lixo, ainda é praticamente inexistente (Centro: $n=75,0 ; 100,0 \%$; João Paulo II: $n=71,0 ; 100,0 \%$ ), isso se dá pela falta de percepção da população sobre Educação Ambiental, visto que não ocorre a sensibilização deles com relação a essa ação, a partir dos órgãos ambientais municipais.

Na pesquisa realizada em Ourinhos - SP por Ferreira et al. (2013), uma grande maioria dos entrevistados $(n=66,0 \%)$ não praticam a separação dos resíduos domiciliares, embora o município disponibilize coleta seletiva. No entanto, no estudo realizado em Ipixuna do Pará todos os entrevistados de Ipixuna do Pará ( $n: 146,0 ; 100,0 \%)$ não separam o lixo pelo fato de não existir coleta seletiva na cidade.

Em outras pesquisas sobre esse tema, foi verificado que a prática da segregação não é efetiva de acordo com os dados nelas contidas, em face da não ocorrência da coleta seletiva, por isso, as comunidades analisadas não efetuam essa ação (Figura $5)$. 
Figura 5. Dados comparativos nos estudos efetuados em Ipixuna do Pará, Pombal e Cascavel quanto a segregação/separação (sim/não) do lixo.

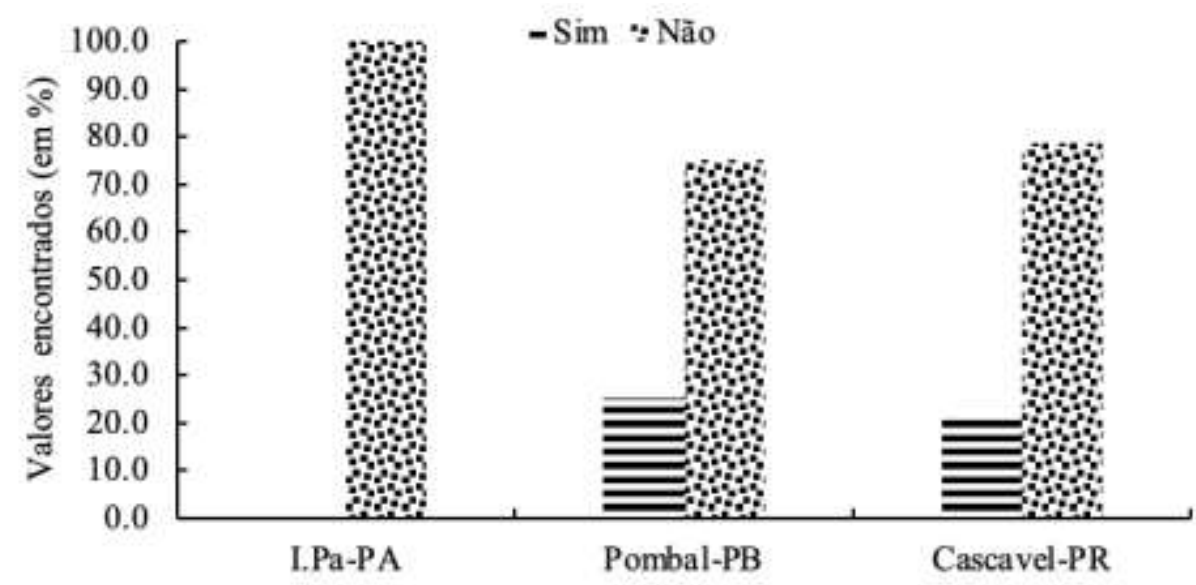

\section{Comparações interpesquisas}

Legenda: I. Ipixuna do Pará. Fonte: Autores (2020).

Observa-se claramente na Figura 5 que a localização geográfica dos municípios não anula as ações ambientais negativas quanto a não segregação residual, especialmente a doméstica. Isso porque em Ipixuna do Pará, nos bairros Centro e João Paulo II, foram obtidos os mesmos valores para a quadra A $(n=24,0 ; 100,0 \%)$, já para a Quadra B, os dados obtidos indicaram que em todas as ER's $(n=25,0 ; 100 \%)$, quanto no bairro João Paulo II ( $n=23,0 ; 100,0 \%)$ não pratica a segregação/separação do lixo. Para a mesma pergunta, na quadra C, os entrevistados afirmaram que não separam o lixo doméstico: bairro Centro ( $n=26,0 ; 100 \%)$; bairro João Paulo II $(n=24,0 ; 100,0 \%)$.

Já na pesquisa no município de Pombal-PB, por Martins et al. (2014), os dados analisados indicaram que a maioria dos entrevistados $(n=75,0 \%)$ não faziam a separação do lixo (Ex.: seco do molhado), e a minoria $(n=25,0 \%)$, efetuavam a separação. Em Cascavel-PR, por Servat et al. (2011), acerca da separação, essa percentagem foi menor ainda (21,4\%). Entretanto, quando interrogados se anteriormente haviam realizado a separação do lixo doméstico, a maioria $(n=42,9 \%)$ deles afirmaram já ter realizado. Na pesquisa efetuada em Ipixuna do Pará, a análise dos dados indicou que em ambos os bairros analisados os entrevistados não separam o lixo, e isso disponibiliza nutrientes e energia para a proliferação de animais sinantrópicos transmissões de doenças à comunidade.

\subsubsection{Questão 2 (Percepção dos indivíduos amostrados quanto ao lixo).}

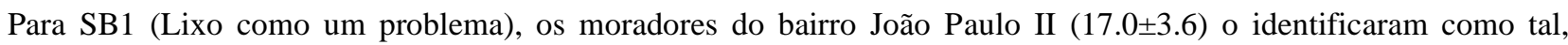

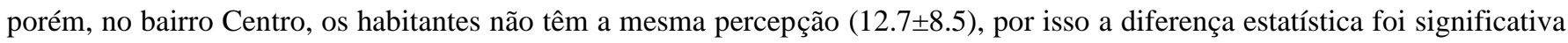
$(4,3)$. Com relação aos dados obtidos à essa questão, fez análise individual para cada subitem que a compõe. Quanto a SB2 (Nesse bairro, o lixo é coletado?), em ambos os bairros analisados, os residentes participantes da pesquisa, afirmaram que sim; Centro $(25,0 \pm 1,0)$, João Paulo II $(20.7 \pm 14.9)$, contudo, não se observou unanimidade, já que há diferença significativa, em torno de 5,0\% (Tabela 3). 
Tabela 3. Valores para as médias e desvios padrões quanto a percepção dos indivíduos amostrados acerca do lixo nesses dois bairros. Ipixuna do Pará, nordeste paraense.

\begin{tabular}{|c|c|c|c|c|}
\hline \multicolumn{5}{|c|}{ Questão 2: percepção dos indivíduos quanto ao lixo } \\
\hline \multirow[b]{2}{*}{ Subitens } & \multicolumn{2}{|c|}{ Sim } & \multicolumn{2}{|r|}{ Não } \\
\hline & -.--.-. & $\overline{\boldsymbol{x}} \pm \sigma_{-} \ldots$ & --.---.. & $\pm \sigma_{-} \ldots$ \\
\hline & Centro & João Paulo II & Centro & João Paulo II \\
\hline SB1. Você Considera o lixo um problema? & $12.7 \pm 8.5$ & $17.0 \pm 3.6$ & $12.3 \pm 8.0$ & $10.0 \pm 3.5$ \\
\hline SB2. Nesse bairro, o lixo é coletado? & $25.0 \pm 1.0$ & $20.7 \pm 14.9$ & $9.3 \pm 14.5$ & $4.5 \pm 5.2$ \\
\hline $\begin{array}{l}\text { SB3. Você considera o número de coletas } \\
\text { suficiente? }\end{array}$ & $22.0 \pm 1.0$ & $16.0 \pm 4.4$ & $8.3 \pm 11.0$ & $11.5 \pm 4.7$ \\
\hline $\begin{array}{l}\text { SB4. Você conhece ou já ouviu falar em } \\
\text { coleta seletiva? }\end{array}$ & $14.3 \pm 3.1$ & $10.0 \pm 15.3$ & $12.0 \pm 4.4$ & $21.0 \pm 6.1$ \\
\hline SB5. A coleta que aqui ocorre, é seletiva? & $0.0 \pm 00$ & $0.0 \pm 0.0$ & $16.3 \pm 41.2$ & $35.0 \pm 0.6$ \\
\hline
\end{tabular}

Fonte: Autores (2021).

Os dados obtidos também indicaram que, em relação a SB1, as visões dos indivíduos amostrados divergem quanto a

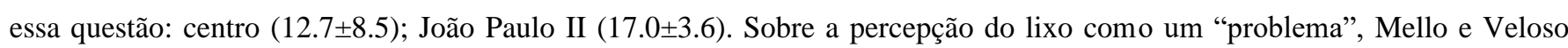
(2013), efetuaram estudo no município de Alto das Pombas-BA, e concluíram que os moradores daquela localidade consideraram o lixo "um grande problema", e a razão foi o deslocamento pois deslocamento do contêiner para armazenamento temporário, do início da rua até a parada final do coletivo urbano que serve a comunidade. Para eles, foi algo negativo, visto, que a maioria não quer se deslocar do início da rua até o final de linha para colocar o lixo naquele receptor.

Na pesquisa realizada em Ipixuna do Pará, a razão é diferente: não há contêiner para armazenamento temporário, por isso a comunidade pratica o chamado "end of pipe" (final do tubo, em português). Nesse caso, ela retira o lixo da residência e o deposita ao longo da calçada e, em muitos casos, no passeio das quadras A (Figura 6a), quadra B (Figura 6b) ou quadra C (Figura 6c).

Figura 6. a) Deposição de lixo na Quadra A; b) Na quadra B. c) Quadra C. bairro João Paulo II, Ipixuna do Pará, nordeste paraense.

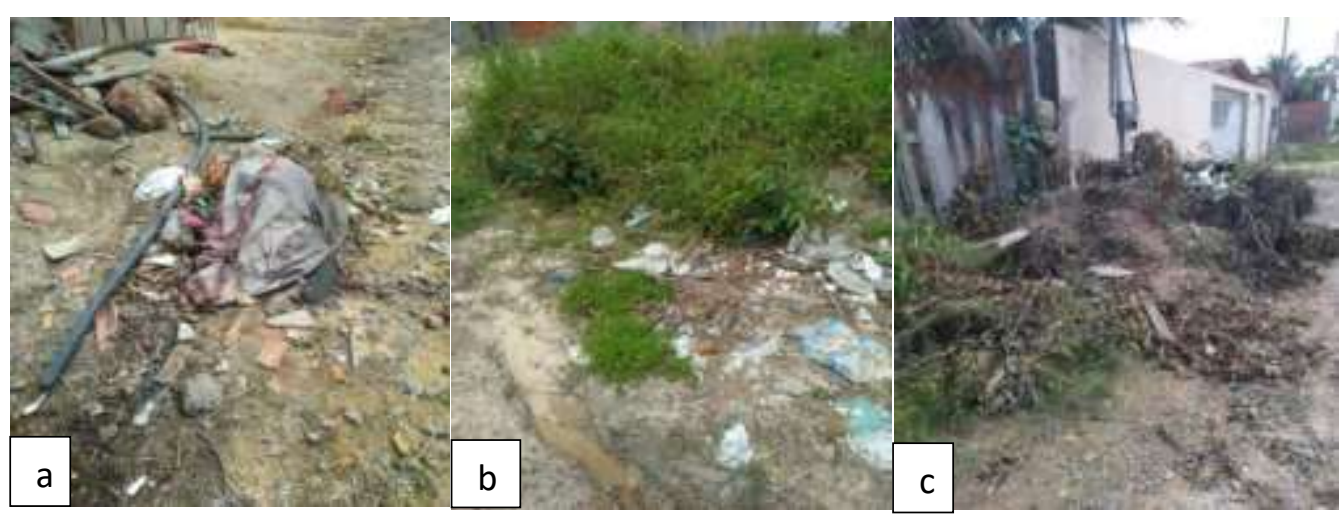

Fonte: Autores (2021).

É notório que a disposição inadequada ocorrem em qualquer quer seja a arterial ou via no subsistema urbano em Ipixuna do Pará, conforme pode ser observado nas Figuras 6a, 6b, e 6c, onde constatou-se que os resíduos de vegetação de roça dos quintais, também chegam ate a área externa das unidades residências, como se observa na Figura 6c, como trata-se de via com declive, poderá ocorrer arrasto disso até a parte mais baixa da rua e provocar um alagamento nela, prejudicando a saúde e o bem-estar de outros moradores dela. 
As consequências dessas deposições inadequadas, são: 1) decomposição dos resíduos orgânicos de forma aeróbica; 2) proliferação de invertebrados como a Musca domestica, transmissora de até 300 tipos de microrganismos patogênicos (bactérias) que provocam infecções estomacais, intoxicações e pneumonia. Nelas, eles estão concentrados nas asas e nas pernas. Acerca dessa relação desarmônica interespecífica, Junqueira et al. (2017) realizaram pesquisas com 116 tipos de moscas de três continentes e verificaram que a doméstica provoca dispersão microbiana de bactérias como a Helicobacter pylori. Então a disposição do lixo doméstico de forma incorreta pode acarretar, em Ipixuna do Pará, disseminação de bactérias e provocar doenças como infecções estomacais graves e crônicas.

Para SB2, o problema no bairro João Paulo II $(n=9,0 ; 12,7 \%)$ é a não chegada da coleta em todas as residências, visto que: a infraestrutura das ruas é precária (Figura 7a), o que impossibilita o carro da coleta chegar até a essas residências, por essa razão ao longo das ruas da quadra existe muitos resíduos domésticos espalhados pelas ruas (Figura 7b).

Figura 7. a) Visão frontal da rua Travessa da paz, no bairro João Paulo II; b) Deposição de lixo na mesma rua. Ipixuna do Pará, nordeste paraense.

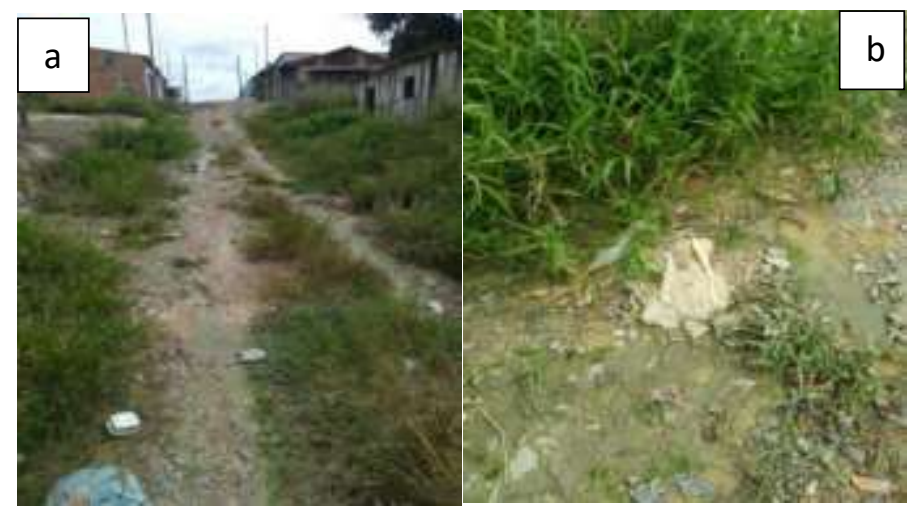

Fonte: Autores (2021).

A Figura 7a deixa evidente o estreitamento da ria e o declive que nela ocorre, bem como a dispersão da vegetação para a via de fluxo veicular e, com isso, o caminhão coletor de lixo, especialmente aqueles com scrubber, podem acessá-la para efetuar a coleta. Outro fato que chama a atenção é quanto a disposição inadequada observada na Figura 7b, especialmente nas vias públicas, especialmente de vasilhas plásticas de poliestireno expandido (EPS, sigla em inglês) ou isopor. oriundas de delivery, que prejudicam não só o meio ambiente, mas a própria saúde da comunidade que ali habita, devido ao tempo de decomposição dele no meio já que o estireno é derivado do petróleo., embora seja 100\% reciclável e reutilizável.

No estudo efetuado por Oliveira, Costa, Meira (2017) no município de Santarém-PA, sobre essa ação, eles concluíram que, de acordo com os moradores de lá, a maioria $(n=125,0 ; 93,0 \%)$ afirmaram que a coleta ocorre, mas uma minoria $(n=9,0 ; 7,0 \%)$ responderam que não. Logo, há uma similaridade entre as duas pesquisas, visto que em Ipixuna do Pará, nos dois bairros analisados, houve confirmação da comunidade quanto a efetividade da coleta de lixo (bairro Centro, $n$ $=75,0 ; 100,0 \%$; bairro João Paulo II, $n=62,0 ; 87,3 \%$ ).

Com relação ao SB3 (Você considera o número de coletas suficiente?), os valores das medias obtidas para o bairro

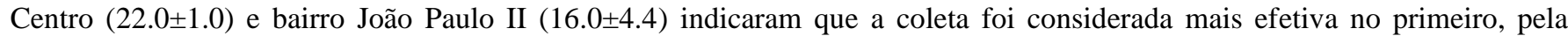
maioria dos residentes nessa localidade $(n=66,0 ; 88,0 \%)$, porém no segundo, ela não atende a todos os moradores $(n=48,0$; 67,6\%). Sobre esse tema, foi realizada uma pesquisa em Humaitá - AM, por Crispim (2019). Nela, os dados indicaram que a insuficiência na coleta atinge a metade dos moradores do bairro São Sebastião $(n=50 \%)$ localizado na periferia daquele município. Dessa forma, os dados obtidos na pesquisa realizada em Ipixuna do Pará, no bairro periférico João Paulo II, foram superiores $(n=66 \%)$ quando comparado a pesquisa realizada Humaitá. 
Para SB4 (Conhecimento sobre coleta seletiva), os moradores, tanto do bairro Centro (12.0 \pm 4.4$)$ quanto do bairro

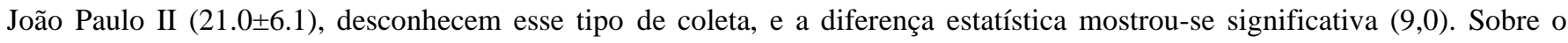
assunto abordados, no estudo efetuado em Santarém-PA, por Oliveira et al. (2017), a frequência de ocorrência de respostas atribuídas a questão "Você sabe o que é coleta seletiva" ( $n=127,0 ; 95,0 \%)$ dos entrevistados afirmaram que sabem o que é coleta seletiva, e a minoria $(n=7,0 ; 5,0 \%)$ afirmou não saber o que é coleta seletiva. Nesse sentindo, a pesquisa realizada em Ipixuna do Pará, nos dados obtidos pelos indivíduos amostrados pois, principalmente no bairro João Paulo II, os entrevistados $(n=41,0 ; 57,7 \%)$ não apresentam conhecimentos sobre a coleta seletiva.

Já no SB5 (Existe coleta seletiva no bairro onde você mora?) esse tipo de coleta foi menos efetiva no bairro Centro

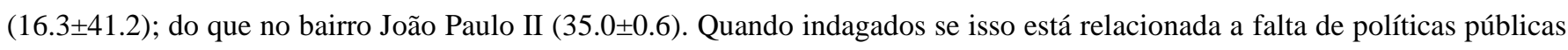
voltadas para questão do lixo, todos os indivíduos amostrados $(n=146,0 ; 100,0 \%)$ afirmaram que não. Porém de acordo com a Lei n 12.305 (2010) que institui a Política Nacional de Resíduos Sólidos, o sistema de coleta seletiva deve ser implantado pelo titular do serviço público de limpeza urbana e manejo de resíduos sólidos, a coleta seletiva representa a maneira ecológica mais adequada para o descarte de lixo, cuja consequência lógica e a mitigação quanto a proliferação de vetores transmissões de doenças à população municipal.

Sobre isso, no estudo efetuado em Campina Grande - PB, por Pereira (2016), os moradores de dois condomínios, A e $\mathrm{B}$, se havia a prática da coleta seletiva pelos órgãos responsáveis. Ele concluiu que, em $\mathrm{A}$, a maioria afirmou que sim $(n=$ $85 \%)$ e, em B $(n=77 \%)$. Em Ipixuna do Pará, os dados obtidos indicaram que não existe esse tipo de coleta.

\subsubsection{Questão 3 (Quantas vezes o lixo é coletado?)}

A análise dos dados indicou que a coleta dos resíduos sólidos ocorre no bairro Centro, em seis dias da semana

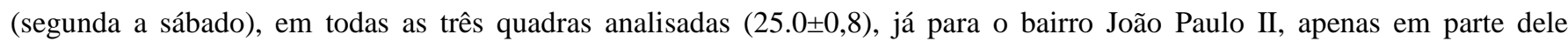
(20.7士4.0), o que representa uma diferença estatística significativa $(4,3)$ na média de resposta quando comparados entre si (Tabela 4).

Tabela 4. Valores de média e desvio padrão, sobre a percepção dos entrevistados dos bairros centro e João Paulo II, para o período de coleta dos resíduos. Ipixuna do Pará, nordeste paraense.

\begin{tabular}{|c|c|c|c|c|}
\hline \multirow{3}{*}{ Subitens } & \multirow{2}{*}{\multicolumn{2}{|c|}{$\begin{array}{l}\text { Segunda a sábado } \\
-\bar{x} \pm \sigma \\
-\end{array}$}} & \multicolumn{2}{|c|}{ Não é coletado } \\
\hline & & & \multicolumn{2}{|c|}{$\bar{x} \pm \sigma$} \\
\hline & Centro & João Paulo II & Centro & João Paulo II \\
\hline Quantas vezes o lixo é coletado? & $25.0 \pm 0,8$ & $20.7 \pm 4.0$ & $0.0 \pm 0.0$ & $3.0 \pm 4.2$ \\
\hline
\end{tabular}

Fonte: Autores (2021).

Para o bairro Centro todos os moradores $(n=75,0 ; 100 \%)$, afirmaram que a coleta é feita semanalmente, no bairro João Paulo II, a maioria $(n=62,0 ; 87,3 \%$ ) dos moradores, corroboraram com aquela resposta, já que há algumas residências onde isso não ocorre $(n=9,0 ; 12,7 \%)$, devido à falta de infraestrutura da rua, o que impossibilita a entrada do carro. Em Urutaí - GO, Rodrigues et al. (2010) realizaram pesquisa acerca da frequência quanto a coleta de lixo, e os dados obtidos indicaram que $18,6 \%$ dos entrevistados responderam que a coleta é realizada diariamente no bairro onde mora; para duas vezes, o porcentual que afirma que é feita duas vezes na semana, se eleva (31\% dos moradores) e, para três vezes, mais ainda (47,3\%); coleta quinzenal ou não souberam responder, as porcentagens foram equivalentes $(1,6 \%)$.

Na pesquisa realizada em Ipixuna do Pará, os dados obtidos e analisados apresentaram divergências com os dados da pesquisa realizada em Urutaí, onde a coleta é realizada em seis dias da semana nos dois bairros. Dessa forma, nota-se que no bairro João Paulo II, uma parcela da população estar sendo prejudicada, visto que a coleta nessa área é inexistente. O que pode 
causar diversas complicações que vão desde poluição visual (pelo acúmulo do lixo que é depositado nas ruas), até a proliferação de vetores causadores de patologias a população.

\subsubsection{Questão 4 (Você sabe onde colocam o lixo depois de coletado?)}

A análise dos dados obtidos indicou que o conhecimento sobre a disposição final dos RS's é elevado nos dois bairros analisados, porém esse conhecimento é mais efetivo no Centro quando comparado ao João Paulo II (Tabela 5).

Tabela 5. Valores para as médias e desvios padrões para as respostas fornecidas pelos entrevistados dos bairros Centro e João Paulo II, quanto o local de descarte do lixo. Ipixuna do Pará, nordeste paraense.

\begin{tabular}{|c|c|c|c|c|}
\hline \multirow[b]{2}{*}{ Subitens } & \multicolumn{2}{|c|}{ Lixão } & \multicolumn{2}{|c|}{ Não sabe } \\
\hline & ------. & $\bar{x} \pm \sigma$ & & $\bar{x} \pm \sigma_{-}$ \\
\hline $\begin{array}{l}\text { Você sabe onde colocam o lixo depois de } \\
\text { coletado? }\end{array}$ & $\begin{array}{l}\text { Centro } \\
17.7 \pm 1.7\end{array}$ & $\begin{array}{l}\text { João Paulo II } \\
12.3 \pm 4.9\end{array}$ & $\begin{array}{l}\text { Centro } \\
7.3 \pm 1.7\end{array}$ & $\begin{array}{l}\text { João Paulo II } \\
11.3 \pm 5.3\end{array}$ \\
\hline
\end{tabular}

Fonte: Autores (2021).

Quanto ao local para onde são transportados e dispostos os lixos coletados, um pouco mais da metade dos moradores do bairro Centro $(n=53,0 ; 70,7 \%)$; acreditam que irá para o vazadouro a céu aberto (lixão); no bairro João Paulo II há uma redução quanto a essa afirmativa $(n=37,0 ; 52,1 \%)$. Em relação ao desconhecimento, no segundo bairro, ela é mais efetiva ( $n$ $=22,0 ; 29,3 \%)$. e para os que afirmam desconhecer o local é ( $n=34,0 ; 47,9 \%)$, com uma diferença estatística significativa $(16,6 \%)$ sobre esse tema.

No estudo efetuado por Oliveira e Costa (2017), em Ponta de Pedras-PA, os dados indicaram que os moradores daquele município não têm coleta domiciliar porque os bairros onde habitam não apresentam condições de trânsito às caçambas coletoras e, com isso, eles depositam em locais situados fora das residências e dos bairros onde habitam, e lá as caçambas coletoras recolhem e conduzem até o "lixão" $(\mathrm{n}=52,1 \%)$ do município. Em Ipixuna do Pará, menos da metade ( $n$ $=41,6 \%$ ) dos indivíduos amostrados afirmaram que a prefeitura recolhe os resíduos, e os leva para o lixão da cidade.

Todavia, esses lixões, que são espaços ao ar livre, normalmente ficam localizados em áreas mais afastadas da cidade, como no município de Ipixuna do Pará, e servem como depósitos para todos os tipos de resíduos são descarregados nessa área. No período chuvoso, haverá geração de chorume, que contribui para a contaminação das águas e do solo, além isso, servem de local de reprodução e habitat para roedores, mosquitos que se depositam em vasilhas (sejam plásticos, latas ou garrafas) onde a água pluvial se acumula, e isso causa incremento nos casos de doenças transmitidas por eles à população.

\subsubsection{Questão 5 (Essa não coleta, você acredita que provoca o aparecimento, na sua casa de ...)}

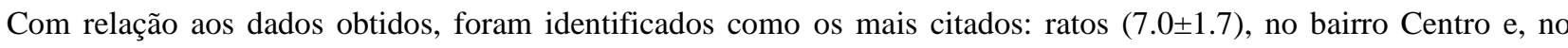
bairro João Paulo II, foram as baratas $(7.3 \pm 1.1)$, dentre os quatro ocorrentes e reconhecidos pelos residentes dessas localidades (Tabela 6). 
Tabela 6. Respostas obtidas a partir das entrevistas efetuadas nos bairros, sobre o aparecimento de vetores nas residências. Ipixuna do Pará, nordeste paraense.

\begin{tabular}{|c|c|c|c|c|c|c|c|}
\hline \multicolumn{8}{|c|}{ Questão 5: Essa não coleta, você acredita que provoca o aparecimento, na sua casa, de: } \\
\hline \multicolumn{2}{|c|}{ Ratos } & \multicolumn{2}{|c|}{ Moscas } & \multicolumn{2}{|c|}{ Mosquitos } & \multicolumn{2}{|c|}{ Baratas } \\
\hline \multicolumn{2}{|c|}{ 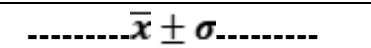 } & \multicolumn{2}{|c|}{$\bar{x} \pm \sigma \ldots \ldots$} & \multicolumn{2}{|c|}{$\bar{x} \pm \sigma \ldots \ldots$} & \multicolumn{2}{|c|}{$\bar{x} \pm \sigma \ldots \ldots$} \\
\hline Centro & $\begin{array}{c}\text { João Paulo } \\
\text { II }\end{array}$ & Centro & $\begin{array}{c}\text { João Paulo } \\
\text { II }\end{array}$ & Centro & $\begin{array}{c}\text { João Paulo } \\
\text { II }\end{array}$ & Centro & João Paulo II \\
\hline $7.0 \pm 1.7$ & $6.7 \pm 1.5$ & $6.0 \pm 1.0$ & $6.7 \pm 2.0$ & $6.3 \pm 1.5$ & $3.0 \pm 1.0$ & $5.7 \pm 1.1$ & $7.3 \pm 1.1$ \\
\hline
\end{tabular}

Fonte: Autores (2021).

Foram identificados pelos indivíduos amostrados mais dois invertebrados de maior frequência nos dois bairros: Centro (mosquitos, $n=19,0 ; 25,3 \%$; moscas $n=18,0 ; 24,0 \%$ ). No bairro João Paulo II (mosquitos, $n=9,0 ; 12,7 \%$; moscas, 20,0; 28,2\%). Sobre esses vetores, Coimbra et al. (2011), efetuaram um estudo em Rodeiro-MG, e os dados que eles obtiveram, os permitiram afirmar que a proliferação desses tipos de vetores em unidades residenciais, atualmente, é um dos maiores problemas frequentes que os órgãos de gestão ambiental e de saúde enfrentam nos municípios brasileiros.

Em relação a este aspecto, novamente, a maior frequência de aparecimento de vetores foi atribuída às áreas mais próximas dos três tipos de unidades arquitetônicas estudadas (distância 0-500m), sendo que 67,3\% dos entrevistados afirmaram que a presença de moscas unidades ER, ocorrem diariamente. Com relação à pesquisa realizada em Ipixuna do Pará, há uma similaridade com a efetuada em Rodeiro (MG), pois, em ambas as pesquisas os vetores mais mencionados pelos moradores foram ratos, moscas e baratas.

3.2.6 Questão 6 (Você sabe que esses animais podem transmitir doenças aos moradores? Se conhece indique uma).

Quanto a esse tipo de informação/conhecimento, a análise dos dados obtidos indicou que em ambos os bairros (Centro,

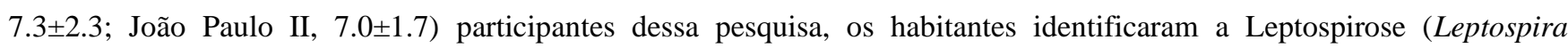
Interrogans), de forma literalmente unanime (Tabela 7).

Tabela 7. Valores de média e desvio padrão, sobre a percepção dos entrevistados do bairro Centro e João Paulo II, para as doenças transmitidas por vetores. Ipixuna do Pará, nordeste paraense.

\begin{tabular}{|c|c|c|c|c|c|c|c|c|c|}
\hline \multicolumn{10}{|c|}{ Questão 6: Você sabe que esses animais podem transmitir doenças aos moradores? Se conhece indique uma: } \\
\hline \multicolumn{2}{|c|}{ Malária } & \multicolumn{2}{|c|}{ Dengue } & \multicolumn{2}{|c|}{ Zica Vírus } & \multicolumn{2}{|c|}{ Leptospirose } & \multicolumn{2}{|c|}{ Não sei } \\
\hline \multicolumn{2}{|c|}{$\bar{x} \pm \sigma-$} & \multicolumn{2}{|c|}{$\bar{x} \pm \sigma$} & \multicolumn{2}{|c|}{$\bar{x} \pm \sigma$} & \multicolumn{2}{|c|}{$\bar{x} \pm \sigma$} & \multicolumn{2}{|c|}{$\bar{x} \pm \sigma-\ldots$} \\
\hline Centro & $\begin{array}{c}\text { João } \\
\text { Paulo } \\
\text { II }\end{array}$ & Centro & $\begin{array}{c}\text { João } \\
\text { Paulo } \\
\text { II }\end{array}$ & Centro & $\begin{array}{c}\text { João } \\
\text { Paulo } \\
\text { II }\end{array}$ & Centro & $\begin{array}{c}\text { João Paulo } \\
\text { II }\end{array}$ & Centro & $\begin{array}{c}\text { João } \\
\text { Paulo II }\end{array}$ \\
\hline $5.0 \pm 2.0$ & $2.0 \pm 2.0$ & $6.7 \pm 1.1$ & $6.0 \pm 1.0$ & $0.3 \pm 0.6$ & $1.0 \pm 1.7$ & $7.3 \pm 2.3$ & $7.0 \pm 1.7$ & $5.7 \pm 1.5$ & $7.7 \pm 1.5$ \\
\hline
\end{tabular}

Fonte: Autores (2021).

É importante ressaltar que no bairro João Paulo II, há residentes $(n=23,0 ; 32,4 \%)$ que não souberam identificar ou pelo menos citar de algumas dessas doenças tem ocorrência onde eles habitam. No estudo efetuado por Vieira et al. (2012), no município de Blumenau-SC, os dados por eles obtidos indicaram que a diarreia foi a doença mais citada, principalmente em crianças, sendo relacionada ao lixo. Houve ocorrência de outras enfermidades como as doenças parasitárias, Salmonelose, disenterias e leptospirose. Já, na pesquisa realizada em Ipixuna do Pará, os dados analisados indicaram que houve uma divergência como estudo efetuado em Blumenau, já que a diarreia foi a mais citada pela comunidade, e na pesquisa de Ipixuna a mais citada foi a doença leptospirose. Porém, o fator gerador de vetores causadores dessas duas patogenias está relacionado ao acúmulo do lixo, independente da biogeografia. 


\subsubsection{Questão 7 (Quanto ao lixo produzido na sua casa, quais os mais frequentes?)}

Os dados obtidos e analisados para essa questão indicaram que a maioria dos indivíduos amostrados, no Bairro Centro $(12.3 \pm 1.1)$ e João Paulo II (14.3 \pm 1.5$)$, identificaram o plástico como o lixo mais produzido nas casas deles $(n=80,0 ; 54,8 \%)$, vale ressaltar que outros tipos de resíduos também foram citados (Tabela 8).

Tabela 8. Valores de média e desvio padrão, dos bairros Centro e João Paulo II, sobre a percepção dos moradores em relação ao lixo produzido em suas residências. Ipixuna do Pará, nordeste paraense.

\begin{tabular}{|c|c|c|c|c|c|}
\hline \multicolumn{6}{|c|}{ Questão 7: Quanto ao lixo produzido na sua casa, quais os mais frequentes? } \\
\hline \multicolumn{2}{|c|}{ Restos de alimentos } & \multicolumn{2}{|c|}{ Plásticos } & \multicolumn{2}{|c|}{ Papel } \\
\hline \multicolumn{2}{|c|}{$\bar{x} \pm \sigma$} & \multicolumn{2}{|c|}{$\bar{x} \pm \sigma$} & \multicolumn{2}{|c|}{$\bar{x} \pm \sigma \ldots$} \\
\hline Centro & João Paulo II & Centro & João Paulo II & Centro & João Paulo II \\
\hline $11.0 \pm 1.0$ & $9.0 \pm 2.0$ & $12.3 \pm 1.1$ & $14.3 \pm 1.5$ & $1.6 \pm 1.5$ & $0.3 \pm 0.5$ \\
\hline
\end{tabular}

Fonte: Autores (2021).

Foi verificado também que há ocorrência de uma produção elevada de resíduos sólidos orgânicos úmidos (restos de alimentos) no bairro João Paulo II $(n=27,0 ; 38,1 \%)$. Como a coleta de lixo é deficitária nesse bairro, isso pode ser uma das razões para ocorrências ocorrência de Leptospirose, já que há alimentos e habitat disponíveis para acasalamento e reprodução. Já no bairro Centro $(n=33,0 ; 44,0 \%)$, pode-se afirmar que há grande produção de resíduos de alimentos, devido a alta concentração de bares, restaurantes, lanchonetes, hotéis e pensões. Dessa forma também foi um fator estimulante à proliferação dos ratos e ocorrência daquela doença.

Em relação ao plástico como o resíduo domiciliar mais gerado, foi efetuado um estudo em Lagoa da Roça-PB, por Querino (2015) concluiu que o plástico foi o material mais citado $(n=54 \%)$, resto de alimentos com $(n=17 \%)$, papel $(n=$ $16 \%)$, fraldas descartáveis $(n=5 \%)$, dentre outros e apenas uma pequena parte da população $(n=1 \%)$ não souberam responder. Na pesquisa realizada em Ipixuna do Pará, os dados obtidos do bairro Centro e João Paulo II, apresentaram similaridade com pesquisa a pesquisa realizada em Lagoa da Roça, pois, em ambas, os resíduos plásticos são os mais produzidos pelos indivíduos amostrados. Isso representa um sério problema ambiental, visto que, as sacolas plásticas demoram cerca de 450 anos para se decompor, prejudicam a vida dos animais em especial as espécies marinhas e causam o entupimento da drenagem urbana. Além disso, a maioria das sacolas plásticas são utilizadas apenas uma única vez e logo depois são descartadas, o que faz com que a produção dela seja alta.

\subsubsection{Questão 8 (Como você embala o lixo produzido na sua casa?)}

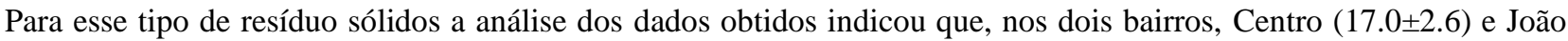

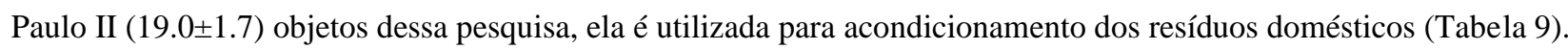

Tabela 9. Respostas dos entrevistados do bairro Centro e João Paulo II, sobre o modo de embalar o lixo. Ipixuna do Pará, nordeste Paraense.

\begin{tabular}{|c|c|c|c|c|c|}
\hline \multicolumn{6}{|c|}{ Questão 8: Como você embala o lixo produzido na sua casa? } \\
\hline \multicolumn{2}{|c|}{ Sacolas plásticas } & \multicolumn{2}{|c|}{ Baldes } & \multicolumn{2}{|c|}{ Caixas } \\
\hline \multicolumn{2}{|c|}{${ }_{-} \bar{x} \pm \sigma}$. & \multicolumn{2}{|c|}{$\bar{n}_{\bar{x}} \pm \sigma_{\ldots} \ldots$} & \multicolumn{2}{|c|}{$\ldots \bar{x} \pm \sigma \ldots$} \\
\hline Centro & João Paulo II & Centro & João Paulo II & Centro & João Paulo II \\
\hline $17.0 \pm 2.6$ & $19.0 \pm 1.7$ & $6.3 \pm 4.1$ & $3.0 \pm 1.0$ & $1.6 \pm 0.6$ & $1.6 \pm 2.8$ \\
\hline
\end{tabular}

Fonte: Autores (2021). 
Foi observado também que as caixas de papelão, que podem ser dobráveis e aproveitáveis para compras nos supermercados pelos munícipes, são utilizadas em ambos os bairros, Centro $(1.0 \pm 0,6)$ e João Paulo II $(1,6 \pm 2,8)$, são destinadas ao armazenamento dos resíduos sólidos domésticos. Na pesquisa realizada em Saubara-BA, por Figueiredo (2013), os dados que ele obteve indicaram que todos entrevistados utilizavam três formas de acondicionamento do lixo: sacolas plásticas $(n=$ $67 \%)$; lixeiras plásticas $(n=18 \%)$; latas e tambores $(n=15 \%)$.

Sobre a mesma questão, foi efetuado um estudo em Medianeira-PR por Mucelin e Bellini (2008). Esses pesquisadores concluiram que a maioria dos indivíduos amostrados $(n=88,0 ; 100,0 \%)$, disseram ter o hábito de usar sacolas plásticas para armazenar o lixo principalmente aquelas fornecidas pelos supermercados e mercearias. Na pesquisa realizada em Ipixuna do Pará, nos dois bairros, Centro $(n=51,0 ; 68,0 \%)$ e João Paulo II ( $n=57,0 ; 80,3 \%)$, a maioria dos indivíduos amostrados utilizavam sacolas plásticas para embalar o lixo. Então, o uso desse tipo de embalagem faz parte do cotidiano da população, independente do espaço geográfico que elas ocupem como, por exemplo, Saubara-BA e Medianeira-PR.

\subsubsection{Questão 9 (Desses lixos que você produz na sua casa que podem ser reaproveitados, reutilizados ou vendidos para evitar a proliferação de animais causadores de doenças)}

A percepção ambiental dos indivíduos amostrados quanto as ações citadas na pergunta, após a análise dos dados obtidos, são parcas porque uma parte significativa deles desconhece o que pode ser inserido naquelas ações, e isso ocorreu

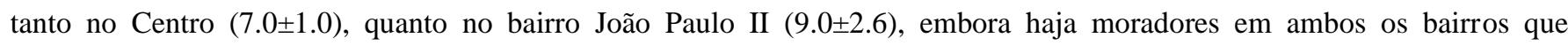
conhecem outras embalagens utilizadas com as proposições inseridas na questão 9 (Tabela 10).

Tabela 10: Valores de média e desvio padrão, sobre a percepção dos entrevistados sobre os resíduos produzidos que podem ser reaproveitados. Ipixuna do Pará, nordeste paraense.

Questão 9: Dos lixos que você produz na sua casa que podem ser reaproveitados, reutilizados ou vendidos para evitar a proliferação de animais causadores de doenças:

\begin{tabular}{|c|c|c|c|c|c|c|c|}
\hline \multicolumn{2}{|c|}{ Garrafa PET } & \multicolumn{2}{|c|}{ Embalagens plásticas } & \multicolumn{2}{|c|}{ Latas de alumínio } & \multicolumn{2}{|c|}{ Não sei } \\
\hline \multicolumn{2}{|c|}{${ }_{-\cdots} \bar{x} \pm \sigma \ldots$} & \multicolumn{2}{|c|}{${ }_{-\cdots} \bar{x} \pm \sigma_{-\cdots} \ldots$} & \multicolumn{2}{|c|}{ 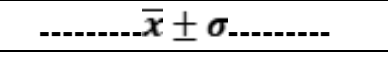 } & \multicolumn{2}{|c|}{${ }^{\prime}-\ldots \bar{x} \pm \sigma \ldots$} \\
\hline Centro & $\begin{array}{c}\text { João Paulo } \\
\text { II }\end{array}$ & Centro & $\begin{array}{c}\text { João Paulo } \\
\text { II }\end{array}$ & Centro & $\begin{array}{c}\text { João Paulo } \\
\text { II }\end{array}$ & Centro & João Paulo II \\
\hline $9.3 \pm 2.1$ & $8.0 \pm 1.1$ & $6.6 \pm 1.1$ & $5.3 \pm 0.5$ & $2.0 \pm 2.0$ & $1.3 \pm 1.5$ & $7.0 \pm 1.0$ & $9.0 \pm 2.6$ \\
\hline
\end{tabular}

Fonte: Autores (2021).

Os dados também indicaram que, para os indivíduos amostrados, a garrafa de Poliacrilato de Etila (PET) foi a mais citadas por eles, e nisso houve uma similaridade entre os dois bairros: Centro $(n=28,0 ; 37,3 \%)$; João Paulo II ( $n=24,0$; $33,8 \%)$. O que chamou a atenção foi que os indivíduos amostrados não inseriram a garrafa PET como "embalagem plástica": Centro $(n=20,0 ; 26,7 \%)$; João Paulo II $(n=16,0 ; 22,5 \%)$.

Em relação a esse tipo de identificação residual pela população, Crispim (2019), realizou uma pesquisa no município de Humaitá-AM, e os dados por ele obtido e analisado, indicaram que a comunidade daquela localidade sabe que há embalagens que podem ser reciclados e/ou reutilizados porque citaram várias: (a) Garrafa PET $(n=327,0)$; (b) latas de Refrigerante $(n=303,0)$; (c) papel/caixas de papelão $(n=285,0)$; (d) revistas/jornais $(n=280,0)$. Além do (e) Óleo de cozinha $(n=274,0)$. Na pesquisa realizada em Ipixuna do Pará, pode-se analisar que houve semelhanças com estudo efetuado em Humaitá-AM, apesar do número de indivíduos amostrados ter sido menor, em ambas as pesquisas, a garrafa PET foi o resíduo mais citado pelos entrevistados, como lixo que pode ser reaproveitado. 


\section{Conclusão}

Foram encontradas diversas problemáticas de cunho ambiental que podem influenciar diretamente na saúde da população em geral. Uma delas é a ausência de coleta seletiva, o que representa um grande problema, já que a separação do lixo, facilita a separação, embalagem e venda do material destinado a reciclagem, o que reduz os impactos gerados pelo consumo desenfreado que ocorre diariamente pela população. Visto que, por meio da reciclagem os resíduos são transformados em matérias-primas e utilizados novamente na geração de novos produtos.

Em uma das vias da quadra $\mathrm{A}$, bairro João Paulo II, foi identificado que não há coleta de lixo devido à falta de infraestrutura dessa via, que torna inacessível o acesso do carro de lixo para coleta em todas as residências. O que resulta em um grande acúmulo dos resíduos domiciliares, tanto nas ruas como nas áreas sem servidão social, localizadas às proximidades desse bairro. Logo, facilidade de proliferação de vetores sinantrópicos.

A frequência da coleta em ambos os bairros, é semanal, no entanto, no bairro João Paulo II é ineficiente, pois os moradores afirmam que durante a coleta os garis deixam cair lixo nas ruas com frequência, dessa forma, observa-se a dispersão do lixo em diversos pontos do bairro. Por outro lado, existe também a falta de sensibilidade da população, com relação a disposição final temporária, já que parte da comunidade prefere fazer de áreas sem servidão social, local da disposição final dos resíduos produzidos nas residências deles.

Quanto a embalagem utilizada para armazenamento do lixo, ela é realizada de forma incorreta, ou seja, em sacolas plásticas, o que facilmente podem ser rasgadas por animais como, por exemplo, os cães que, para se alimentarem da matéria orgânica (restos de alimentos) neles, contidos, expõe o que excesso que irá nutrir vetores sinantrópicos e contribuir para a proliferação deles. Além disso, os resíduos sólidos gerados pela população são armazenados no lixão, o que é muito prejudicial à fauna e a flora porque contamina o solo e a água e, com isso, diminui as áreas para plantios de leguminosas, olerícolas e outros cultivos nutricionais, o que encarece o valor desses produtos agrícolas à comunidade de baixa renda como aquela do bairro João Paulo II.

Dessa forma, a prefeitura juntamente com a Secretaria de meio ambiente, devem desenvolver políticas públicas que possam minimizar essas problemáticas no município, entre elas palestras e oficinas educativas com a população para sensibilizá-los, dos problemas decorrentes do descarte irregular dos resíduos domésticos. Além, de proporcionar uma coleta seletiva para a população, o que beneficiaria tanto no quesito ambiental como econômico, visto que a reciclagem tem importância econômica, tanto para o município como para a geração de mais empregos voltados para essa área.

Torna-se necessário, a partir dos dados contidos nessa pesquisa, possam ser intensificados, tanto pela Secretaria Municipal de Meio Ambiente (SEMMA), quanto pela Secretaria de Viação e Obras Públicas: 1) o monitoramento da coleta de lixo; 2) reestruturação quanto a rota, número de caminhões e de garis, para melhor atender a população; 3) realização de oficinas nas comunidades ou bairros para ensinar o modo correto de embalar os resíduos domésticos; 4) fornecimento e calendários que mostrem os dias de coleta; 5) criar um canal de comunicação onde os moradores possam encaminhar sugestões e reclamações e, (6) aplicação de multas quanto à disposição final inadequada do lixo.

Já a Secretaria Municipal de Saúde, deve gerar dados a partir da Unidade de Pronto Atendimento (UPA), Unidade Básica de Saúde (UBS), Unidades de Saúde da Família (USF), ou postos de Saúde, quanto a evolução da ocorrência de doenças transmitidas por vetores que utilizam resíduos orgânicos como alimentos e, em seguida promover uma busca e inspeção no bairro onde reside o indivíduo contaminado para, em seguida, repassar à Secretaria Municipal de Meio Ambiente, ou à Secretaria de Serviços Urbanos, deficiências encontradas naquele bairro.

Recomenda-se também o desenvolvimento de outras pesquisas tanto para monitoramento e geração de novas informações acerca do problema do lixo urbano nesse município, ou naqueles que são limítrofes a ele, com especial atenção à 
coleta seletiva, cujos dados aqui contidos podem ser a base para verificação uma evolução/involução quanto ao gerenciamento desse tipo de resíduo.

\section{Referências}

Bessa, M., Carvalho, M. F., Silva, S. W. S, Souza, J. O., Vieira, F. G., \& Freitas, R. J. M. (2020). Implicações do lixo no processo saúde/doença: um relato de experiência. Revista Saúde e Meio Ambiente, 11(2), 50-60. https://periodicos.ufms.br/index.php/sameamb/article/view/11151.

Britto, Júnior, A. F., \& Feres Júnior, N. M. (2011). A utilização da técnica da entrevista em trabalhos científicos. Evidência, 7(7), 237-250. https://met2entrevista.webnode.pt/_files/200000032-64776656e5/200-752-1-PB.pdf

Coimbra, J. B. Oliveira, M. D., \& Azevedo, M. A. (2011). Impactos ambientais e na saúde ocasionados pela destinação de resíduos sólidos em lixão e em unidades de triagem e compostagem. Universidade Federal de Viçosa. Recuperado de https://aidisnet.org/wp-content/uploads/2019/07/277-Brasil-oral.pdf.

Crispim, M. C. F. N. (2019). Matriz de sustentabilidade e análise da percepção ambiental em relação aos resíduos sólidos domiciliares no sudoeste do amazonas. (Dissertação de mestrado). Universidade Federal do Amazonas, Humaitá, AM, Brasil. Recuperado de https://tede.ufam.edu.br/handle/tede/7423

Figueiredo, E. C. (2013). Análise da percepção ambiental frente ao gerenciamento de resíduos sólidos do município de Saubara-BA. (Monografia, Especialização em Gestão Ambiental). Universidade Tecnológica Federal do Paraná, Medianeira, PR, Brasil. http://repositorio.roca.utfpr.edu.br/jspui/bitstream/1/4519/1/MD_GAMUNI_2014_2_34.pdf

Ferreira, J. M., Poletto, R. S., Batista, G. J., Cunha, C., \& Machado, T. A. (2013). A destinação do lixo e a importância da educação ambiental no ensino fundamental. Diálogo e Interação, (7), 1-11. http://www.faccrei.edu.br/wp-content/uploads/2016/10/diartigos84.pdf

Firmo, C. E. F. (2010). Ocorrência de surtos alimentares em escolas de educação básica. (Monografia, Especialização em Microbiologia Ambiental e Industrial). Universidade Federal de Minas Gerais, Belo Horizonte, MG, Brasil. http://hdl.handle.net/1843/BUOS-99UJ2X

Follador, K., Prado, G. P., Passos, M. G., \& Nothaft, S. C. (2015). Saneamento básico: meio ambiente e saúde. Revista UNINGÁ Review, 23(1), 24-28. http://revista.uninga.br/index.php/uningareviews/article/view/1636.

Gutjahr, A. L. N., Araújo, L. J. B., Matos, E. S., \& Braga, C. E.S. (2014). Diagnóstico e Mapeamento das Fontes de Contaminação do Rio Ipixuna, Estado do Pará, Brasil. Enciclopédia Biosfera, 10(19), 2092-2107. Recuperado de https://conhecer.org.br/ojs/index.php/biosfera/article/view/2446.

IBGE. (2018). Produção Agrícola Municipal. área plantada, produção e produtividade de soja, 2002-2017. https://sidra.ibge.gov.br/tabela/5457

Jacinski, L. (2017). Desenvolvimento de questionário para coleta e análise de dados de uma pesquisa em substituição ao modelo Google Forms. (Trabalho de

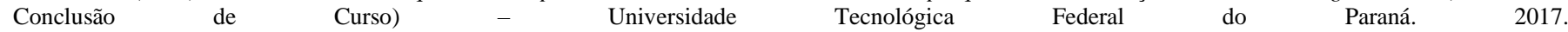
http://repositorio.roca.utfpr.edu.br/jspui/bitstream/1/8339/1/PG_COADS_2017_2_06.pdf.

Junqueira, A. C. M., Ratan, A., Acerbi, E., Drautz-Moses, D. I., Premkrishnan., Costea, P. I., Linz, B., Purbojati, R. W., Paulo, D. R., GUALTIER, n. g., Subramaniam, P, Hasan, N. R., Colwell, R. R., Peer B., Azeredo-Espin, A. M., Bryant, D. A. \& Schuster, S. (2017). The microbiomes of blowflies and housefies as bacterial transmisión reservoirs. Scientifc Reporters, 7. www.nature.com/articles/s41598-017-16353-x.pdf. http://dx.doi.org/10.1038/s41598-01716353-x.

Lei $n .{ }^{\circ} 12.305$ de 02 de agosto de 2010. Institui a Política Nacional de Resíduos Sólidos; altera a lei n.9.605, de 12 de fevereiro de 1998; e dá outras providencias. http://www.planalto.gov.br/ccivil_03/_ato2007-2010/2010/lei/l12305.htm.

Lei $n,{ }^{\circ} 14026$ de 15 de julho de 2020. Atualiza o marco legal do saneamento básico e altera a Lei $\mathrm{n}^{\circ} 9.984$, de 17 de julho de 2000, para atribuir à Agência Nacional de Águas e Saneamento Básico (ANA) competência para editar normas de referência sobre o serviço de saneamento, a Lei $\mathrm{n}^{\circ} 10.768$, de 19 de novembro de 2003, para alterar o nome e as atribuições do cargo de Especialista em Recursos Hídricos, a Lei no 11.107, de 6 de abril de 2005, para vedar a prestação por contrato de programa dos serviços públicos de que trata o art. 175 da Constituição Federal, a Lei no 11.445 , de 5 de janeiro de 2007 , para aprimorar as condições estruturais do saneamento básico no País, a Lei $n^{\circ} 12.305$, de 2 de agosto de 2010, para tratar dos prazos para a disposição final ambientalmente adequada dos rejeitos, a Lei $\mathrm{n}^{\circ}$ 13.089, de 12 de janeiro de 2015 (Estatuto da Metrópole), para estender seu âmbito de aplicação às microrregiões, e a Lei $\mathrm{n}^{\circ} 13.529$, de 4 de dezembro de 2017, para autorizar a União a participar de fundo com a finalidade exclusiva de financiar serviços técnicos especializados. http://www.planalto.gov.br/ccivil_03/_ato2019-2022/2020/lei/114026.htm.

Maciel, A. B. C., Felipe, J. A., \& Lima, Z. M. C. (2015). Os problemas de saneamento e seus impactos sobre a saúde pública do município de Dona Inês/PB. Revista OKARA, 9(3), 524-541. de http://www.periodicos.ufpb.br/index.php/okara/article/viewFile/22833/14684.

Martins, W. A., Albuquerque, W. G., Nunes, F. M. S., Almeida, R. N., Morais, C. E. P. (2014). Análise da concepção da população do município de Pombal$\mathrm{PB}$, sobre o adequado gerenciamento dos resíduos sólidos. Revista Verde de Agroecologia e Desenvolvimento Sustentável, 9(2), 307-316. https://www.gvaa.com.br/revista/index.php/RVADS/article/view/2958

Mello, L. S., \& Veloso, J. A. (2013). O lixo sempre como um problema? um estudo no bairro Alto das Pombas, em Salvador-Bahia. In: Congresso Nacional de Gestão Ambiental. 5.4, 2013. Anais eletrônicos [...].https://www.ibeas.org.br/congresso/Trabalhos2013/III-057.pdf

Mucelin, C. A., \& Bellini, M. (2008). Lixo e impactos ambientais perceptíveis no ecossistema urbano. Sociedade \& natureza, 20(1), 111-124. https://www.scielo.br/scielo.php?pid=S1982-45132008000100008\&script=sci_abstract\&tlng=pt. https://doi.org/10.1590/S1982-45132008000100008.

Naime, R. (2014). Impactos visíveis dos resíduos sólidos. www.ihu.unisinos.br/noticias/534945-impactos-visiveis-dos-residuos-solidos-artigo-de-roberto-naime.

Oliveira, I. G., \& Costa, S. M. F. (2017). Análise da percepção ambiental dos moradores de área de várzea urbana de uma pequena cidade do estuário do rio Amazonas. Paisagem e Ambiente: Ensaios. (40), 151-167. https://www.revistas.usp.br/paam/article/view/124464. https://doi.org/10.11606/issn.23595361.v0i40p151-167 
Oliveira, J. C., Costa, S. S., \& Meira, R. C. S. (2017). Percepção dos moradores sobre a gestão dos Resíduos Sólidos no bairro Caranazal, no Município de Santarém -PA, Brasil. In: Congresso Brasileiro de Gestão Ambiental. 5.8, 2017. Mato Grosso do sul. Anais eletrônicos [...].http://www.ibeas.org.br/congresso/Trabalhos2017/I-002.pdf.

Oliveira, M. F. (2011). Metodologia científica: um manual para a realização de pesquisas em Administração. Universidade Federal de Goiás. https://files.cercomp.ufg.br/weby/up/567/o/Manual_de_metodologia_cientifica_-_Prof_Maxwell.pdf.

Pereira, A. C., Silva, V. L. M. M., Lima, L. M. R., Crispiniano, F. F., \& Porto, R. M. I. (2016). Percepção ambiental de moradores de condomínios verticais e sua participação nos processos de coleta seletiva na cidade de Campina Grande/PB, Brasil. In: Congresso Brasileiro de Gestão Ambiental. 5.7, 2016. Campina Grande - PB. Anais eletrônicos [...].https://www.ibeas.org.br/congresso/Trabalhos2016/III-065.pdf

Pereira Júnior, A., Silva, E. F. S., \& Bandeira, R. P. (2018). Proposta para o gerenciamento dos resíduos sólidos gerados nas etapas de corte e plainagem do setor moveleiro que utiliza MDF no município de Marabá - PA. Brazilian Applied Science Review, 2(3),807-838. https://www.brazilianjournals.com/index.php/BASR/article/view/458. https://www.doi.org/.

PMSP. (2014). Prefeitura Municipal de São Paulo. Vetores sinantrópicos. Definição. http://puspc.usp.br/wp-conte/uploads/sites/159/2016/08/DefiniçãoVetores_Sinatrópicos.pdf.

Prodanov, C.C., \& Freitas, E. C. (2013). Metodologia do Trabalho Científico: Métodos e Técnicas da Pesquisa e do Trabalho Acadêmico. (2a ed.). São Paulo: Feevaleb.

Querino, L. A. L. (2015). Percepção ambiental acerca dos resíduos sólidos domiciliares: um estudo com os moradores de São Sebastião de Lagoa de Roça $P B$. [Dissertação de mestrado]. Universidade Federal de Campina Grande, Campina Grande, PB, Brasil. http://dspace.sti.ufcg.edu.br:8080/jspui/handle/riufcg/982.

Ribeiro, J. W., \& Rooke, J. M. S. (2010). Saneamento básico e sua relação com meio ambiente e a saúde pública. (Monografia, Especialização em Análise Ambiental). Universidade Federal de Juiz de Fora, Belo Horizonte, MG, Brasil. https://www.ufjf.br/analiseambiental/files/2009/11/TCCSaneamentoeSa\%c3\%bade.pdf.

Rodrigues, A. S. L.; Rezende Neto, O. A.; \& Malafaia, G. (2010). Análise da percepção sobre a problemática relativa aos resíduos sólidos urbanos revelada por moradores de Urutaí, Goiás, Brasil. Enciclopédia Biosfera, 6(11), p. 1-16. https://conhecer.org.br/ojs/index.php/biosfera/article/view/4299.

Schleder, E. J. D., \& Albuquerque, L. B. (2016). Lixo: suas características e alternativa metodológica para aproveitamento da parte orgânica. Multitemas, (10), 75-96. http://www.multitemas.ucdb.br/article/viewFile/1218/1139.

Santos, M. B. (2010). Algumas contribuições ao Projeto Para Viver de bem com os Bichos (PVBB) enfoque: fauna sinantrópica. [Tese de Doutorado]. Universidade de São Paulo, São Paulo, SP, Brasil. https://teses.usp.br/teses/disponiveis/10/10134/tde-23032011-154120/pt-br.php

Servat, A., Chiarello, A. S. G. Quadros, C. S., Magalhães, E. L., \& Carniatto, I. (2011) Coleta seletiva, uma leitura do conhecimento e envolvimento de alguns moradores de Cascavel-PR. In: Simpósio Latino Americano e Caribenho de Educação em Ciências do International Council of Associations for Science Education. 9.4, 2011. Paraná Anais eletrônicos [...].http://www.uel.br/ccb/biologiageral/eventos/erebio/comunicacoes/T178.pdf.

Silva, M. D. S. F., Santos, C. S., Feitosa, F. R. S., \& Santos, R. D. C. (2017). Incidência de dengue em ambiente costeiro: uma análise do bairro Cidade Nova em Aracaju a partir dos condicionantes socioambientais. Os Desafios da Geografia Física na Fronteira do Conhecimento, 1, 1707-1718. https://ocs.ige.unicamp.br/ojs/sbgfa/article/view/2272. https://doi.org/10.20396/sbgfa.v1i2017.2272.

Silva, N. S., Alves, J. B., Silva, E. M., \& Lima, R. R. (2020). Avaliação da Relação Entre a Climatologia, as Condições Sanitárias (Lixo) e a Ocorrência de Arboviroses (Dengue e Chikungunya) em Quixadá-CE no Período Entre 2016 e 2019. Revista Brasileira de Meteorologia, 35(3), 485-492. https://www.scielo.br/scielo.php?pid=S0102-77862020005008203\&script=sci_arttext. https://doi.org/10.1590/0102-77863530014.

Varanda, T. A. (2015). Otimização de toras e redução dos custos de operação da coleta seletiva. (Trabalho de Conclusão de Curso). Universidade Aberta do Brasil, Barretos, SP. https://bdm.unb.br/bitstream/10483/14024/1/2015_ThiagoAntonioVaranda.pdf.

Vieira, P. C., Silveira, J. L. G. C., \& Rodrigues, K. F. (2012). Percepção e hábitos relacionados ao lixo doméstico entre moradores da comunidade do Coripós, Blumenau, SC. Revista de APS, 15(1), 82-91. https://periodicos.ufjf.br/index.php/aps/article/view/14779. 